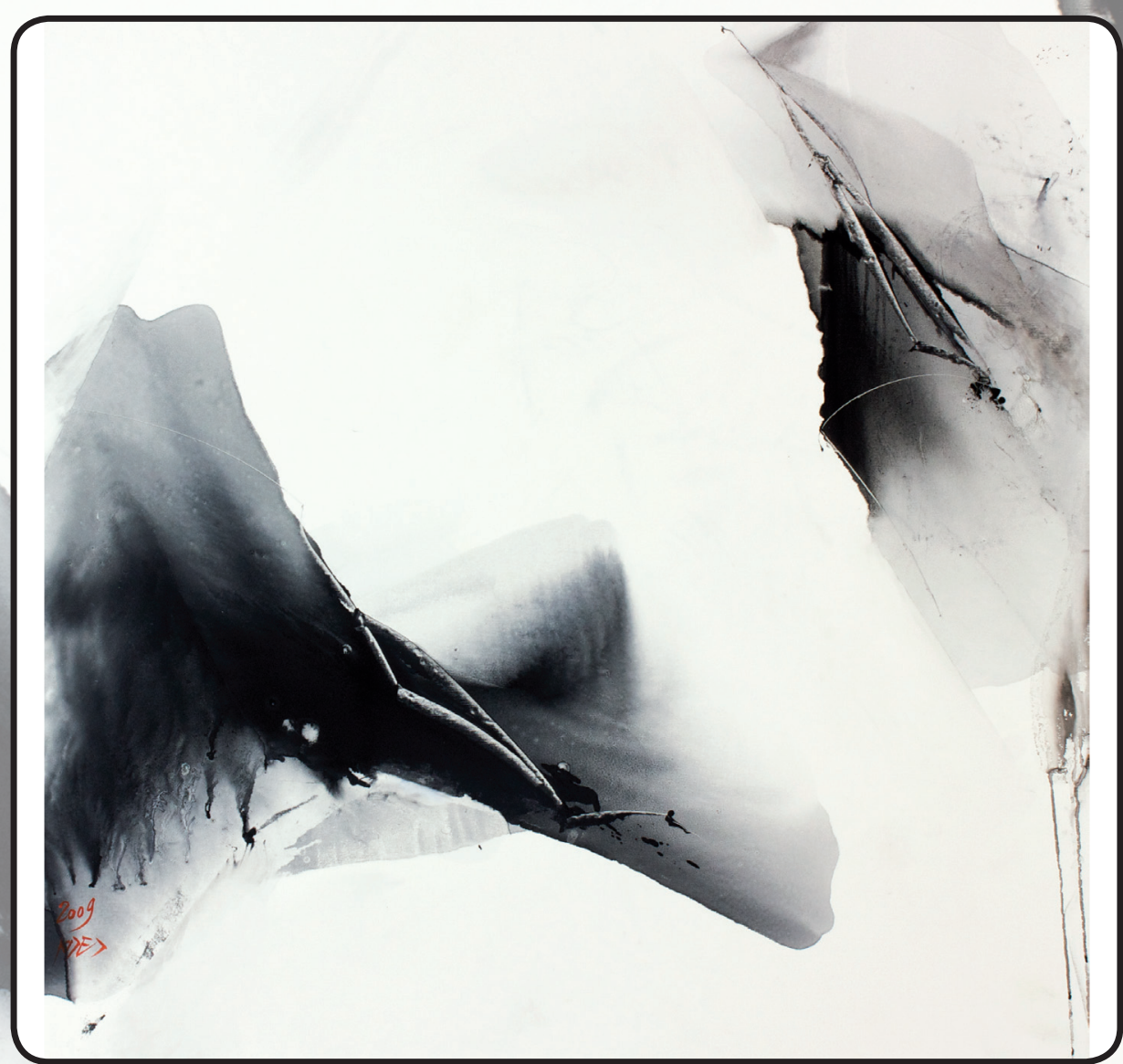


Hommage Aux 12 apotres

Óleo sobre lienzo

$120 \times 120 \mathrm{cms}$

2009

Colección Privada

Universidad Santo Tomás 


\title{
EL DERECHO EN LA ERA DIGITAL: EL PROBLEMA DE LA REGULACIÓN DE LAS RELACIONES JURÍDICAS SURGIDAS EN INTERNET
}

\section{Manuel Eduardo Marín Santoyo}

Abogado Universidad Santo Tomás - Seccional de Bucaramanga (Col); Especialista en Contratación Internacional Universidad Externado de Colombia; Docente, Universidad Santo Tomás - Seccional Bucaramanga (Col). E: mail: manuelmarin6@gmail.com

\begin{abstract}
Resumen
El avance tecnológico que se ha presentado en el mundo y específicamente en las comunicaciones por medio del Internet ha conllevado la aparición de circunstancias relevantes en el mundo del derecho. Lo anterior desligado de que el Internet se ha convertido en un espacio donde se generan todo tipo de relaciones (familiares, sociales y comerciales). Se hace relevante y pertinente abordar el estudio de las herramientas que tiene el derecho para regular dichas circunstancias, la validez y eficacia del derecho vigente frente a la regulación del Internet y, derivado de ello, buscar qué derecho se debe aplicar para poder plantear un panorama general de la perspectiva del derecho frente al nuevo reto que se genera con la digitalización de las relaciones sociales, de acuerdo a las soluciones frente a la ley y la jurisdicción aplicables a dichas relaciones y a la forma como se debe regular un sistema social que diariamente sufre transformaciones.
\end{abstract}

\section{Palabras clave}

Red global mundial, globalidad territorial, mensaje de datos, servidor, contrato de hosting.

\begin{abstract}
The technological breakthrough was made in the world and specifically in communications through the Internet has led to the emergence of relevant circumstances in the legal world. This isolation from the Internet has become a place where they generate all kinds of relationships (family, social and commercial). Becomes relevant and pertinent to address the study of the tools we have the right to regulate such circumstances, the validity and effectiveness of existing law against Internet regulation and derived from it, find out what law should apply to present a panorama overall perspective of the right facing the new challenge is generated by the digitization of social relations, according to the solutions before the law and jurisdiction applicable to such relationships and the way it should regulate a social system that suffers daily transformations
\end{abstract}

\section{Key Words}

World wide web, global planning, data message, server hosting contract. 



\section{EL DERECHO EN LA ERA DIGITAL: LA PROBLEMÁTICA DE LA REGULACIÓN DE LAS RELACIONES JURÍDICAS EN INTERNET*}

Manuel Eduardo Marín Santoyo

\section{Generalidades del Internet}

A causa del avance tecnológico en que se ha visto inmerso el mundo es menester realizar un estudio sobre cuál debe ser la labor del derecho dentro de este desarrollo y bajo cuáles presupuestos se debe empezar a realizar su adecuación para integrarse a las nuevas necesidades, dentro del cual se generan circunstancialmente más situaciones que tienen relevancia jurídica. De esta manera se debe iniciar por encontrar las raíces de la más grande red global de transmisión de datos como es el Internet para, a partir de ello, buscar las implicaciones jurídicas que se generan dentro de ella.

Internet y los demás medios de transmisión de datos tienen sus raíces en la investigación militar y sus posteriores adecuaciones, hasta llegar a la conocida World Wide Web o la parte comercial del Internet, a través de la cual se empieza a globalizar el uso de la red, que surge en los años noventa con los sistemas de navegación eficiente (browser), que entraron a facilitar la interacción en los sitios de la red

Esta red tiene como base una serie de elementos técnicos como son:

El texto hace relación a la revisión del tema del Derecho en el marco de la Era Digital, la problemática jurídica del internet, derivada del avance de la tecnología, y la incidencia que este medio puede tener en las relaciones jurídicas, así como un planteamiento de soluciones a la misma. 
“a) Redes de Telecomunicaciones, públicas o privadas, b) Protocolos, tagramas, direcciones IP, c) Computadores Personales, teléfonos celulares y cualquier aparato electrónico que permita la navegación, y d) Servidores y computadores de tamaño y capacidad suficiente para alojar las páginas" (Peña y Burgos, 2003, 1-2).

Lo anterior ha llevado a que Internet sea un medio de transmisión de datos de fácil acceso casi desde cualquier punto del mundo y por parte de todo tipo de personas, por lo cual dentro de su funcionalidad ha incluido una serie de bienes físicos y de bienes intangibles que tienen circulación permanente y funcional dentro del andamiaje y funcionamiento de la red, los cuales como se analizará implican un cambio de concepción para el derecho que encuentra en el uso de estos bienes una serie de circunstancias que desligadas de ello tienen relevancia jurídica.

Como primera medida se hace necesario revisar el carácter que tiene la red en sí misma, sí debe ser concebida simplemente como un espacio virtual almacenador de datos o, por el contrario, según su uso, el cual ha trascendido del concepto tecnológico, para convertirse en un espacio generador de relaciones sociales que requieren ser analizadas y reguladas por el derecho. De esta manera, debemos volver al concepto que se exploró en principio con respecto al avance del Internet que inicialmente, y cuando su uso era meramente de investigación militar, cumplía con la función de almacenamiento y transmisión de datos entre ordenadores con una sola destinación (manejo para operaciones e información militar). Sin embargo, tras la aparición del World Wide Web y la manera como el sistema browser efectivizó el acceso y la forma de interactuar dentro de la red, se generó de forma sistemática que las personas encontraran en Internet una manera fácil de poner en contacto los dos extremos de cualquier tipo de relación (comercial, entre consumidor y productor, hasta de índole familiar y sentimental), de esta manera, Internet ha trascendido hasta volverse una red social dentro de la cual se desarrolla todo tipo de relaciones, lo que conlleva a que, desde el punto de vista económico, se aproxime a un verdadero mercado ${ }^{1}$, desde el punto de vista personal, un espacio de convergencia a partir del cual se crean relaciones de todo tipo e inclusive de trascendía familiar. Desde el sistema estatal es una herramienta democrática a través de los cuales los gobiernos se acercan a sus súbditos y realizan procedimientos que sirven para dar visos de transparencia y de mayor acceso a las prerrogativas del Estado² (Peña, 2003 p. 21).

1 Se debe entender como un mercado por ser un espacio en el que se generan todas las fases de la relación comercial, es decir, se genera la oferta, la demanda y se concreta todo el intercambio comercial de bienes y servicios tanto en relaciones b2b (productor- productor), b2c (productorconsumidor) , c2c (consumidor- consumidor), g2c (Gobierno Consumidor) y p2p (entre iguales) todas de sus siglas en Inglés.

2 Se ha usado de parte de los Estados los denominados gobiernos en línea o E-government, a través del uso de portales .gov (p.p tomado de: Daniel Peña Valenzuela (DIR), Andrea Burgos Puyo, el contrato de diseño, desarrollo y hosting de un sitio de Internet, Universidad Externado de Colombia, 2003, p. 21 


\section{La problemática jurídica del Internet}

Desligada de las características generales del Internet, aparece una situación imperiosa y apremiante para el derecho, como lo es la existencia de gran cantidad de situaciones que en el mundo físico tienen una regulación cierta pero que no tienen la misma en el espacio virtual, por lo cual se debe entrar a evaluar en primera medida la suficiencia y validez de las normas existentes frente al desarrollo de las relaciones que se generan en Internet o si, por el contrario, se encuentran elementos diferentes que hacen especial la regulación que debe tener el derecho frente a las relaciones nacientes de Internet.

Para dar respuesta a la situación planteada se estudia los aspectos jurídicos de la red y cuáles son las situaciones que podrían generar problemáticas diferentes a las ya solucionadas por el derecho.

Desde el punto de vista de la red, la problemática jurídica se aprecia desde situaciones derivadas de la globalidad de la misma, en las cuales la presencia de la falta de certeza frente a cuál es la norma que debe regir la relación jurídica que se presenta en línea, conlleva dificultades para poder regular las relaciones y solucionar eventuales conflictos que se generen en el desarrollo de las mismas. La globalidad territorial implica la posibilidad de acceder a la red desde diversos lugares del mundo, sin importar ubicaciones geográficas y con capacidad de desarrollar relaciones en tiempo real (concomitantemente), entre personas que se encuentran distantes; ello hace que las relaciones que se generan en Internet presentan problema frente al principio general de la territorialidad de la ley, pues, en las relaciones de Internet se presentan circunstancias donde encontramos personas ubicadas en dos lugares diferentes con unas leyes territoriales aplicables a cada una de ellas, al interior de una misma situación jurídica. Es de anotar que no es problema alguno las relaciones que se generan en Internet, entre personas que a pesar de estar ubicados en lugares diferentes, lo están dentro de un mismo territorio nacional o tienen normas comunes de aplicación para el manejo de estas relaciones (ejemplo personas que se ubican en lugares que tienen coberturas de normas supranacionales, como sucede en la Unión Europea y en la Comunidad Andina de naciones, en temas como propiedad intelectual), ya que la norma aplicable a este caso no es otra que la norma propia del territorio nacional donde se encuentren las personas o, en su defecto, la norma supranacional creada por la organización internacional gubernamental correspondiente (Tremolada, 2007).

La implicación importante para analizar respecto de la regulación del Internet es la que se genera en el caso de la ubicación en territorios nacionales diferente o sin reglas comunes a las personas que hacen parte de una relación de cualquier tipo generada en Internet. Ante la situación se genera un caso donde la territorialidad de dos normas entra en conflicto, ya que tenemos personas que tienen por estar establecidas en Estados diferentes la cobertura de sus normas nacionales o supranacionales según sea el caso, por lo tanto se debe, a partir de ello, buscar qué solución existe en el 
derecho para poder subsanar esta situación, que podría no generar inconveniente cuando las normas de ambos territorios estatales tienen contenidos o sentidos idénticos o similares, pero que implican problema frente a normas de sentido diverso, ante normas de naciones de tradición consuetudinaria frente a normas de naciones con tradición jurídica Romanista.

Para dar claridad al punto observar el ejemplo de una la compraventa realizada por Internet de un software entre un inglés (comprador, de tradición consuetudinaria) y un colombiano (vendedor, tradición Romanista), y qué sucedería en este contrato, si el bien vendido se destruye a causa del naufragio por mal tiempo en el trayecto. Frente al vendedor existen los exonerantes legales de responsabilidad (caso fortuito y fuerza mayor), como alegables válidamente para, de ser el caso, eximentes de responsabilidad, pero, de parte del comprador, son inexistentes a menos de que se pacten cláusulas contentivas de los mismos dentro del contrato. De esta manera encontramos una situación en que las dos partes de la relación tienen normas distintas para la aplicación, las cuales implican una solución distinta la una de la otra, razón por la cual le sería imposible a cualquier operador jurídico dar solución de forma concreta, ya que la misma nace de una red global que no tiene una normatividad propia por lo cual es imposible encontrar una norma común. Por ello es importante encontrar qué respuesta actual tiene el derecho frente a la dificultad fáctica que se presenta en las relaciones que se generan dentro de la red global.

\section{Soluciones a la problemática jurídica del Internet}

\section{La autorregulación}

La primera solución es la llamada autorregulación, que hace referencia a la creación de una serie de normas similares a las de los códigos deontológicos ${ }^{3}$, que rijan de forma uniforme las relaciones que nacen de Internet y que buscarían generar reglas únicas y uniformes en la red.

El principal inconveniente de esta solución es encontrar el mecanismo para que dicho instrumento tenga de alguna manera fuerza vinculante que genere obligatoriedad en su aplicación, esta es una dificultad habida cuenta que no existe con respecto a la red un organismo supranacional con competencia legislativa, por lo cual la única forma vinculante para que se generase bien sea este organismo o cualquier forma normativa general sería mediante la firma de un tratado internacional, que tiene como dificultad su negociación y, además, su limitada cobertura, pues sólo tendría aplicación a los Estados firmantes del mismo. A partir de la autorregulación

3 El código deontológico es entendido como el conjunto de reglas y deberes morales que impone el ejercicio de una profesión, sobre todo en el ejercicio de profesiones liberales. Enciclopedia Descubrir, Salvat Editores S.A. Tomo A-L pág. 137. 
la solución más práctica sería el crear un órgano supranacional que regule las relaciones de forma adecuada y pertinente o el que las partes de toda relación en Internet definieran las normas aplicables a la misma (lo cual tiene la dificultad de la norma nacional imperativa).

\section{Las recomendaciones de los institutos internacionales}

Otra alternativa es la usada por los diversos institutos que manejan el tema como son: Comisión de las Naciones Unidas para el derecho mercantil internacional (CNUDMI), le Institut Ineternational Pour L'unification Du Droit Prive (UNIDROIT) y la Cámara de Comercio Internacional de París $(\mathrm{CCI})^{4}$, que generan normas y recomendaciones que pueden ser usadas por las partes dentro de una relación como normas aplicables al contrato o que en ocasiones son recogidas por normas nacionales (ejemplo en Colombia Ley 527 de 1999, sobre comercio electrónico que es una recopilación de estas recomendaciones). Sin embargo, el problema de la solución a través de firma de tratados o de acogimiento como norma nacional de las recomendaciones dadas por institutos internacionales tienen como desventaja, que mientras se realizan los trámites correspondientes muchas veces (como sucede en Colombia), por los avances tecnológicos en Internet al culminar el trámite para formalizar la normativa, los contenidos de estas normas ya se encuentran obsoletos frente a nuevos y más avanzados métodos que se usan en la red.

\section{El Derecho Internacional Privado}

Otra solución la otorga el derecho internacional privado a partir de la forma como el mismo encuentra la ley aplicable a una relación jurídica en la que existen diversas normas aplicables en razón a que la misma contenga elementos de extranjería o de internacionalidad $^{5}$. El problema respecto de las denominadas normas de conflicto frente a la situación que se desliga de Internet es la existencia de varios factores especiales que tienen injerencia en la relación jurídica surgida en Internet; ya que a diferencia de las relaciones clásicas, en Internet no sólo tienen injerencia las dos partes que integran una relación, por ejemplo, de índole contractual o personal, sino que adicional a ellas aparecen otros sujetos que tienen injerencia directa por

4 Para más información sobre estas organizaciones ver sitios Web de la Comisión para las Naciones Unidas para el derecho mercantil internacional www.uncitral.org, el Instituto Internacional para el Derecho privado www.unidroit.org, la Organización Mundial de Negocios www.iccwbo.org

5 Para el tema de Internet y específicamente de la globalidad territorial este elemento está dado por que las partes de la relación jurídica estén residenciadas en lugares distintos, tomando el concepto de residencia como lugar desde donde se encuentra de manera permanente y desde donde se celebra el negocio (para el caso el lugar físico de ubicación) o donde se van a generar los efectos del mismo, lo anterior para evitar usar el concepto de domicilio de la persona, que implica la posibilidad de la existencia de varios respecto de un solo individuo y por lo tanto complicaría más aun la situación problemática frente a las relaciones generadas en la red. 
ser proveedores del medio usado para que las partes puedan concretar la relación jurídica; así las cosas, podría, aparecer el sujeto (persona natural o jurídica) dueño del servidor que hospeda la página Web desde donde se genera el mensaje de datos; que puede ser el dueño mismo de ella o puede, a su vez, tener un contrato de hosting con un tercero que sea su manejador (en caso de existir, sería otra parte implicada dentro de la relación jurídica); los dos sujetos especiales a las relaciones generadas en Internet tienen injerencia en la misma y, por lo tanto, pueden terminar afectados con las situaciones desligadas de ella; como antecedente válido está el conocido como caso YAHOO (Ramírez, 2007), donde un juez francés encontró responsable a Yahoo como propietario de un servidor que hospedaba páginas (mediante contrato de hosting gratuito), que contenían imágenes nazis y antisemitas y subastaban artículos de esta misma orientación, ante lo cual fue condenado el dueño del servidor (Yahoo Inc.) por violar la ley penal francesa en el artículo R.645-2 de su Código penal. Con este antecedente está como adicional a las relaciones jurídicas, el que en aquellas que se generan en la red, entran a tener injerencia sujetos especiales con unas responsabilidades y deberes desligados del deber de custodia ${ }^{6}$, que implican en algunos casos el hecho de ser garante de la operación realizada (caso como el que acontece en las subastas on-line, en las que pueden ser vinculados como garantes de un subastador o subastante que han sido habilitados y calificados de su parte para participar en la puja correspondiente).

Lo anterior envuelve que, ante la multiplicidad de posibles sujetos dentro de la relación dada en la red, se presente claramente una circunstancia de complejidad frente a la ley y la jurisdicción aplicable al caso, es decir, a cómo se debe solucionar la circunstancia de cuál debe ser el juez competente para conocer o solucionar las controversias surgidas de esta relación y cuál la norma se debe aplicar para dar solución a la misma. Esta situación puede solucionarse a partir de la posibilidad del uso de las normas de conflicto ${ }^{7}$ que se encuentren dentro del ordenamiento jurídico de cada uno de los países en cuyos territorios tengan asiento las partes de la relación; sin embargo, la situación empieza a tomar más complejidad en casos como el colombiano ${ }^{8}$ donde no existen normas de conflicto completas para las situaciones que se presentan en

6 El deber de custodia que recae sobre el dueño de un servidor o el propietario o usuario (mediante contrato de hosting), por los contenidos en una página Web se han tratado en casos como los de Cubby vs. Compuser Inc., Playboy Vd. Frena, Sega Vd. Maphia, entre otros, en los que tribunales de justicia han condenado o absuelto a los dueños de servidores o de páginas Web por responsabilidades desligadas del deber de custodia sobre los contenidos de las páginas Web hospedadas por su servidor o de las que se tiene su uso o propiedad.

$7 \quad$ Norma de conflicto es toda aquella que define cual es la ley o la jurisdicción aplicable a una relación jurídica que tenga elementos de internacionalidad.

8 En Colombia son muy pocas las normas de conflicto contempladas en el ordenamiento jurídico y solo hacen referencia a contratos que tengan efectos en el extranjero, a la capacidad de las partes, a la forma de los instrumentos y a el estado civil de las personas (artículos 19 y 20 Código Civil Colombiano) 
Internet o cuando se implica de entrada que no existe norma que dé certeza a cuál debe ser el territorio que prima dentro de la relación o cuáles deben ser los factores que deben definir la ley y la jurisdicción aplicable 9 . Ante lo anterior, se propone que se debe estudiar cuáles son los posibles territorios que tienen incidencia en la relación surgida en la red, ante lo cual debemos encontrar básicamente lo siguiente; como primera medida, se tendrían que observar la existencia de varios criterios para fijar la competencia del juez que conocerá la controversia y, además de lo anterior, cuál es la ley que deberá aplicar.

Conforme a lo anterior, se tendría que observar que si la relación de Internet está cubierta por la Convención de Viena sobre compraventa de mercadería, se aplicaría la ley y la jurisdicción del lugar donde se cumpla la prestación característica ${ }^{10}$; embargo, debe observarse que, como las normas de la Convención de Viena de 1980 tienen una aplicación restringida ${ }^{11}$, dentro de la cual se excluyen muchas de las relaciones de Internet habida cuenta que muchas transacciones que se realizan en la red no corresponden a contratos de compraventa de mercaderías, sino que las que sí son casi siempre responden a contratos de consumo personal los cuales se excluyen de la aplicación de la convención conforme al artículo segundo.

De esta manera es necesario configurar unos criterios para la elección de ley y jurisdicción aplicables en el caso de las demás relaciones que no se encuentran contempladas en la anterior circunstancia, por lo tanto, se debe abordar el tema de cuáles serían los criterios ante una relación diferente a la de la compraventa o de una compraventa que no sea cubierta por la Convención de Viena. Para ello existen varios sujetos con posibles implicaciones de carácter jurídico en la relación surgida de Internet, por lo cual se abarca la forma como se debe fijar el criterio en el caso de que se suscite una controversia en la cual sólo tengan alguna injerencia las partes de la relación jurídica y, en este caso, se encuentra que pueden existir los siguientes criterios para la ley y la jurisdicción aplicables:

Criterio de la elección voluntaria de ley y jurisdicción aplicables. Se refiere a la posibilidad que las partes, dentro de la misma relación y en el acuerdo al que lleguen para su consolidación, determinen cuál sea la ley aplicable a sus controversias y escojan el Juez que se encargue de conocer el proceso derivado de estas controversias. Dicha situación tiene como limitante principal las normas procesales de los Estados; las cuales, por regla general, son de carácter imperativo y público, por lo cual, no

9 A modo de comentario como si lo hace la convención de Viena de 1980 sobre compraventa de mercaderías cuando determina que la ley y la jurisdicción aplicable serán las del lugar donde se realice la prestación característica tomando claramente el principio de lex loci executionis.

10 Ibídem p.12

11 Artículos 1, 2, 3, 4, 5 y 6 de la Convención de las Naciones Unidas sobre los contratos de compraventa internacional de mercaderías", hecha en Viena el once (11) de abril de mil novecientos ochenta (1980), Ratificada en Colombia por la Ley 518 de 1999. 
es posible pasar por encima de ellas y pactar de manera alguna disposiciones en contrario; en el caso colombiano, por ejemplo, las normas sobre competencia ${ }^{12}$ tienen preceptos por los cuales no es posible que el proceso pueda tener inicio en el país si no se adecuan a las situaciones en ellas enunciadas ${ }^{13}$. Desde el punto de vista sustancial existe también el problema de la norma nacional y cómo la misma, si tiene el carácter de imperativa, no permitiría que las partes pactasen voluntariamente una norma aplicable, por ejemplo, en Colombia las disposiciones sobre inmuebles no son susceptibles de que le sean aplicables disposiciones diferentes a las nacionales ${ }^{14}$, de igual manera, se presenta la imposibilidad de que un juez nacional pueda por voluntad de las partes sustraerse de la aplicación de su ley ${ }^{15}$ y que sólo pudiese llegar a aplicar la ley de un Estado diferente en el caso de que aplique las normas de conflicto de los artículos 19 y 20 del Código Civil son las grandes talanqueras a la forma de este criterio. Sin embargo, la aplicabilidad del criterio tiene en la legislación colombiana una posible salida contemplada en el artículo 2 de la ley 315 de 1996 que permite a las partes pactar el arbitraje internacional para la solución de controversias y poder escoger la ley que se aplique a la misma, sin embargo, hay que remitirse al artículo 1 de la misma ley para poder encontrar cuándo es factible acceder a este tipo de arbitraje $^{16}$, pero es esta la forma como se haría viable este criterio para la escogencia de ley y jurisdicción aplicable a las relaciones surgidas en Internet.

Criterio de la elección del primer demandante. Este criterio hace referencia a la posibilidad de que ante una desavenencia surgida de una relación nacida en la red, el juez competente sea el elegido a prevención por la primera de las partes que haga uso de la correspondiente acción y que sea quien determine, según su propia norma de conflicto, cuál ley es aplicable al caso. Este criterio, sin embargo, vuelve a tener la complejidad de que está sujeto a que las normas imperativas de tipo procedimental que rijan al juez elegido le permitan ser competente para el $\mathrm{caso}^{17}$, ante lo cual si se llegase a declarar incompetente se daría conforme a la competencia preventiva la facilidad para que las partes puedan acudir al juez que consideren competente, se aclara, en este punto, que en el Derecho Internacional no existen normas que permitan generar conflictos de competencia entre jueces de Estados diferentes, pero que si existen mecanismos para poder alegar pleito pendiente en otro Estado.

De esta manera se observan los dos criterios para fijar la competencia en caso de que la controversia que surja sólo inmiscuya a las partes directas de la relación

12 Artículos 20 y 23 Código de Procedimiento Civil Colombiano.

13 Por ejemplo procesos que sean derivados de obligaciones contractuales cuando ninguna de las obligaciones del contrato se hayan cumplido en el país, Art. 23 No 5 Código de Procedimiento Civil Colombiano

14 Articulo 20 Código Civil Colombiano.

15 Esta situación tiene como base el artículo 230 de la Constitución política de Colombia que obliga al juez al imperio de la ley nacional.

16 Articulo 1 ley 315 de 1995

$154 \quad$ Ibídem p. 12. 
jurídica, se advierte que no existe, en ninguno de los esbozados, una seguridad que permita definir fácilmente dicha circunstancia.

Ahora, se debe observar qué criterios se deben aplicar cuando la controversia pretenda desligar responsabilidad de parte del propietario del servidor o al propietario o arrendatario de la página donde se generó la relación o a estos dos por igual, para lo cual se deben observar los siguientes criterios:

Criterio de la ubicación del servidor del propietario o arrendatario de la página Web. Según este criterio, la ley y jurisdicción aplicables a un caso que se desprende de una relación surgida en la Web deben ser tenidos en cuenta a partir del lugar en el cual se encuentra ubicado el servidor que hospeda la página en la que se generó la relación por medio de mensaje de datos. Este criterio pese a ser válido, no es suficiente, máxime cuando el servicio o el mensaje de datos ${ }^{18}$ que se mueve por la red puede ser abierto en cualquier otra parte del mundo y por lo tanto puede conllevar consecuencias en lugares diferentes al lugar donde se encuentra ubicado el servidor, razón por la cual no es posible aplicar única y exclusivamente una norma que no va a ser acorde a la del lugar donde surte efectos el mensaje de datos contenido en la Web que es, el que tiene valor pues es el usuario receptor del mismo quien recibe dichos efectos y puede llegar a afectarse de forma directa e inclusive violar una ley local respecto de la cual sí se encuentra obligado a su cumplimiento. Otro argumento adicional al anterior es que de ser el lugar del servidor el que determine la ley y la jurisdicción aplicable puede conllevar un fraude a la ley en el lugar en que se abre el mensaje y que una situación que es convalidada por la ley del país donde se encuentra ubicado el servidor al ser aplicada en un Estado diferente en donde se reciba el mensaje de datos sea atentatoria contra una norma de orden público por lo cual no se debe tomar este criterio como el válido. ${ }^{19}$

Criterio del lugar donde se recibe el mensaje de datos. Según el cual la ley aplicable es la del lugar donde se recibe el mensaje de datos, es decir, el lugar donde el usuario de Internet accede a la página o a los contenidos de la misma. Este criterio es más amplio y aunque más complejo de aplicar es más justo, lo anterior en razón a que es el receptor del mensaje de datos quien le va a generar efectos o no y, por ello, es su ley la que llega a determinar si es legal en virtud de los contenidos que

18 Al respecto se debe determinar que el mensaje de datos es en la Web el medio como se maneja la información y que, por lo tanto, es el que genera en últimas la relación vinculante desde el punto de vista probatorio, ya que es a partir de él que se concreta la relación que se ha entablado. El mismo ha sido definido por la ley colombiana de la siguiente manera: Ley 527 de 1999 ARTÍCULO 2o. DEFINICIONES. Para los efectos de la presente ley se entenderá por: a) Mensaje de datos: la información generada, enviada, recibida, almacenada o comunicada por medios electrónicos, ópticos o similares, como pudieran ser, entre otros, el Intercambio Electrónico de Datos (EDI), Internet, el correo electrónico, el telegrama, el Télex o el Telefax.

19 Esta es una situación que se presenta en el conocido caso Yahoo, para el cual se puede dirigir a la referencia realizada en el pie de página 9 
se encuentran en él. Ejemplo de ello son las políticas anti spam $^{20}$ existentes en solo algunos países del mundo, lo que implicaría que pese a que el servidor desde el que se originen esté en un Estado de los cuales tiene regulación sobre las mismas, la apertura del mensaje en un país en el cual no se tiene dicha regulación, dejaría al receptor del mismo sin acción alguna contra el originador ya que no tendría a su favor la protección legal que contra dichos mensajes se plasme en ordenamientos jurídicos distintos a aquel que le es aplicable por su ubicación espacial. Por todo lo anterior se considera que es este criterio el más válido para analizar cuáles son la ley y la jurisdicción aplicables.

Criterio del domicilio de la empresa propietaria del servidor o del propietario o arrendatario de la página Web. En este criterio se tiene en cuenta el domicilio del propietario del servidor, es decir, donde tiene la empresa el asiento principal de sus negocios y bajo qué nacionalidad desliga su personalidad jurídica. Es un criterio válido pero, complementario al anterior, ya que esta sería una segunda opción, en una especie de competencia preventiva que implica poder tener dos lugares donde demandar, esto aclara que la empresa puede no tener su domicilio en el mismo lugar donde se encuentra su servidor por lo cual es un criterio desligado del primero.

De esta manera se esbozan los criterios que se podrían utilizar para poder elegir las normas que van a regir la relación en Internet. Sin embargo, se debe anotar que la problemática sigue en cuanto a qué sucede con la efectividad de la solución que sea dada por el juez que, en últimas dirima la competencia, es decir, qué sucede con el denominado riesgo de ejecución de las sentencias judiciales, entendido como la efectividad que pueda tener la sentencia cuando vaya a ser ejecutoriada en país diferente a aquel en el cual fue dictada. Ante lo mismo se debe decir que no existe ningún tipo de normatividad especial y que los únicos mecanismos posibles en el mundo son los procedimientos de exequatur y la solicitud de ejecución del sistema norteamericano, y que los mismos tienen la complejidad de que para que la sentencia dictada en otro país sea ejecutable debe no violar ninguna disposición interna de carácter imperativo, lo cual es un problema para la efectividad de una decisión tomada $^{21}$.

20 Spam "es todo aquel correo electrónico que contiene publicidad que no ha sido solicitada por el propietario de la cuenta de e-mail. La actividad de los spammers -aquellos sujetos que se encargan de generar el spam- es considerada poco ética e incluso ilegal en muchos países. Aquellas aplicaciones y herramientas encargadas de detectar o eliminar el spam son llamados programas antispam. El spam puede clasificarse como un tipo de correo electrónico no deseado. Por extensión, spam también se aplica a todo tipo de método de publicidad engañosa, no solicitada u oculta". Tomado del diccionario informático de la página Web http://www.alegsa. com.ar/Dic/spam.php, recuperado el 12 de Noviembre de 2009

21 Ejemplo de ello es lo determinado en el ya citado caso Yahoo, en el cual un juez norteamericano desconoció la sentencia de la justicia francesa y, por lo tanto, no permitió la ejecución de la sentencia en territorio norteamericano. 


\section{CONCLUSIONES}

En el presente escrito se han esbozado algunas circunstancias problemáticas que se presentan para el derecho derivadas del avance de la tecnología y, en especial, del Internet y la incidencia que este medio puede tener en las relaciones jurídicas. A modo de reflexión se podría decir que el Derecho debe reaccionar prontamente ante estos hechos y entender que se deben buscar mecanismos idóneos para poder realizar una correcta regulación jurídica de las situaciones derivadas de Internet para así evitar lo que se ha presentado en diferentes lugares del mundo y específicamente como se presenta en Colombia con la ley 527 de 1999, la cual tomó como base la ley modelo de la $\mathrm{CNUDMI}^{22}$, es hoy casi obsoleta por la existencia de nuevos y mejores mecanismos de carácter tecnológico que han reemplazado los que en ella se contemplan y por lo cual no existe una seguridad jurídica de la forma como pueden ser llevadas las relaciones cibernéticas.

Todo lo anterior habida cuenta, como se ha desarrollado a lo largo del escrito, que las soluciones jurídicas que se pueden generar desde los mecanismos actuales del derecho derivan en situaciones que no son claras y, por el contrario, forjan toda clase de dificultades para la regulación cierta de las relaciones surgidas mediante el Internet, al igual que para la solución de eventuales controversias surgidas en razón o con causa en la mismas. Por ello, es necesario empezar a estudiar en profundidad la forma como se debe afrontar el Internet desde el derecho, y cómo se debe empezar a buscar figuras jurídicas óptimas que eviten los riesgos propios de las soluciones acá exploradas, como son los riesgos de ejecución y de jurisdicción, para esto se debe partir de la revisión desde los diversos escenarios del estudio del derecho, cuáles serían las formas óptimas para generar mecanismos jurídicos legítimos, válidos y efectivos que puedan ser adoptados los cuales, ante todo, busquen romper las barreras estatales de normas imperativas que no permiten encontrar soluciones que estén en consonancia con la velocidad con la cual avanza el Internet y que permitan de alguna forma la fluidez real de un derecho que pueda adaptarse y aplicarse de mejor manera a un espacio generador de relaciones jurídicas, que tienen un desarrollo diferente a las que se generan habitualmente en el mundo físico, derivado de la inmaterialidad y la posibilidad de actuar en tiempo real, por lo cual las soluciones habituales del derecho pueden no llegar a ser óptimas. Por esto se espera desde estudios como estos, se pueda abrir la discusión para que se afronte la realidad que se hace presente hoy y que nos abre las puertas a un mundo que desde lo jurídico sufre cambios sustanciales por la pérdida gradual, pero cierta, de las limitaciones de espacio y tiempo que históricamente se afronta.

22 UNCITRAL por sus siglas en inglés. 


\section{REFERENCIAS}

Peña, D., \& Burgos, A. (2003). El contrato de diseño, desarrollo y hosting de un sitio de Internet. Universidad Externado de Colombia, 2003

Peña, D. (2003). La responsabilidad civil en la era digital. Universidad Externado de Colombia.

Tremolada, E. (2008). El derecho Andino en Colombia. Universidad Externado de Colombia.

Burgos, A. (2007). El consumidor y los contratos en Internet. Universidad Externado de Colombia.

Peña, D. (2007). La responsabilidad civil en la era Digital. Bogotá: Universidad Externado de Colombia.

Oviedo, J. \& Calvo, A. [Directores.] (2006). Colección derecho Y globalización Tomo 2 NUEVA LEX MERCATORIA Y CONTRATOS INTERNACIONALES. Grupo Editorial Ibáñez.

Ramírez, D. (2006). Conflicto de leyes y censura en Internet: ¡El caso Yahoo! Recuperado el 12 de Noviembre de 2009. http://www.publicaciones.cucsh. udg.mx/ pperiod/comsoc/pdf/cys8_2007/cys_n8_8.pdf 